\title{
Article
}

\section{Conjunctivitis and Exposure to Ambient Ozone}

\author{
Mieczysław Szyszkowicz ${ }^{1,}$, , Ariela Gordon Shaag ${ }^{2}$ and Einat Shneor ${ }^{2}$ \\ 1 Population Studies Division, Health Canada, Ottawa, Canada; mietek.szyszkowicz@canada.ca \\ 2 Department of Optometry and Vision Science, Hadassah Academic College, Jerusalem, Israel; \\ arielag@hac.ac.il; eshneor@hac.ac.il \\ * Correspondence: mietek.szyszkowicz@canada.ca
}

\begin{abstract}
The purpose of this study is to assess the concentration-response relations between conjunctivitis and exposure to ambient ozone. This retrospective study includes emergency department (ED) visits for conjunctivitis in Edmonton, Canada, for the period April 1992 - March 2002. Daily average levels of ozone (range: $1.2-50.9, \mathrm{ppb}$ ), of temperature, and of relative humidity were estimated and used for the period of the study. For each of the considered exposure lags, (from 0 to 9 days), six different models were fitted to estimate the concentration-response function. The goodness of fit was assessed using the Akaike information criterion. During the period of the study, 17,211 ED visits for conjunctivitis were recorded and used. For all subjects together, a positive statistically significant association was obtained for the exposure lagged by 5 days. For female subjects, lags 1, 3, and 9 had positive statistically significant associations (lag 2 had negative associations). For male subjects, only lag 5 had a positive statistically significant association. The estimated non-linear concentration-response functions for the considered groups (all, males, females) and lags, revealed the associations along the exposure levels. The fitted shapes are described by algebraic functions and may have various forms. The estimated functions are useful to determine the risk associated with exposure to ground-level ozone.
\end{abstract}

Keywords: Air pollution; Conjunctivitis; Exposure; Linear; Model; Case-crossover; Poisson

\section{Introduction}

This presentation focuses on the methodological aspects of environmental epidemiology. The technique proposed here reveals associations of conjunctivitis with ground-level ozone $\left(\mathrm{O}_{3}\right)$ as concentration-response curves. The goal of the present paper is to re-analyze the data used in the previous publication [1], but with a different methodology. The applied methodology allows fitting various types of concentration-response functions, not only linear, as it is assumed in the traditional technique [2] realized in the form of log-linear models. The original publication only demonstrated the positive statistically significant association for ozone lagged by 5 days. It is interesting to explore these relations more fully and to verify the associations for other lags and also by sex.

The conjunctiva is composed of non-keratinized, both stratified squamous and stratified columnar epithelium, together with interspersed goblet cells. As it is highly vascularized and constantly exposed to the external environment, the conjunctiva is vulnerable to various harmful factors such as viruses, bacteria, allergens, and chemicals, thereby resulting in conjunctivitis [3]. In Canada, the recent report elaborated by the Canadian Association of Optometrists summarizes the issues related to eye diseases [4]. In the United States, three to six million people suffer from conjunctivitis per year $[5,6]$ and it is the most common ocular condition diagnosed in US emergency departments [7-9].

The mechanisms by which air pollution impacts eye health is not clearly understood and several pathophysiological mechanisms may explain this association. Pollutants can damage the tear film and directly expose the corneal and conjunctival epithelium to air pollutants, making the ocular 
surface vulnerable [3,10-12]. Tear film abnormalities and subclinical changes of the ocular surface were found in individuals living in areas with high concentrations of pollutants $[13,14]$.

Conjunctival goblet cells are slow cycling cells that may proliferate in response to chronic inflammatory stimuli [15-17]. Recently, it was found that pollutants can increase the number and density of goblet cells in the conjunctiva [18-21] and increase interleukin-6 (IL-6) and interleukin-8 (IL-8) expressions in pollutant-treated human corneal epithelial cells (HCECs) and conjunctival epithelial cells (HCLEs), [22,23].

In addition, the pollution may increase oxidative stress, thus impeding the antioxidant defenses of the eye and inducing a cycle of inflammation and irritation, which strengthens allergen response, leading to clinical allergic conjunctivitis [24].

Ozone, produced by reactions between nitrogen oxides and volatile organic compounds in a process catalyzed by ultraviolet light, is regarded as one of the most toxic air pollutants to which humans are routinely exposed [25].

Exposure to high concentrations of ozone has been reported to cause damage to the ocular surface and corneal epithelium, and increased inflammatory tear cytokine levels in a mouse model [26]. In addition, exposure to ozone exacerbates deterioration of the ocular surface and amplifies the inflammatory state already induced by an allergic reaction, as evidenced by an increase in conjunctival chemosis, conjunctival injection, and corneal and conjunctival fluorescein staining scores including significant decrease in tear production [27].

The prevalence of conjunctivitis according to sex is not clear. Several studies found a high prevalence of allergic conjunctivitis in females [28-31] while others showed the opposite trend [32].

There is a small number of epidemiological studies which have investigated the association of conjunctivitis with ambient air pollution exposure. Some of these studies indicate ambient ozone as a risk factor for emergency department (ED) visits [1,29] along with other ambient air pollutants [3,33-38]. One of the first studies concerning this connection reported results on the exposure to ground-level ozone and ED visits for conjunctivitis in Edmonton, Canada [1]. The Taiwan multi-city study [33], found a high levels of ozone and increase chances of an ED visit, in the immediate post-exposure period, for the patients suffering from nonspecific conjunctivitis. However, the study tested the cumulative exposure, accumulated in the period of up to 5 days preceding the ED visit. In addition to conjunctivitis, the ozone effects on various skin conditions and cellulitis [1, 39-41].

The standard approach in environmental epidemiology studies is to use log-linear model, in time-series analysis, considering counts or, in case-crossover analysis, considering separate health events. The estimated relative risk (RR) or odds ratio (OR) are usually shown as one value for a specified air pollution concentration level, say D. They are calculated using the exponential function with the estimated coefficient (slope, beta) and concentration $D(R R=\exp (b e t a * D)$ or $\mathrm{OR}=\exp \left(\right.$ beta*$\left.\left.^{*}\right)\right)$. In this paper, we propose using various forms of concentration-response functions, not only exponential. We hypothesize that such an approach will result in a more adequate concentration-response function.

\section{Materials and Methods}

\subsection{Used data}

ED visits for conjunctivitis in Edmonton, Canada, were collected for the period April 1992 March 2002, [1]. The data on ED visits were organized by Alberta Health Services-Edmonton Zone for all five major acute care hospitals in the Edmonton area. In this 10 year time period, 2,951,878 diagnosed ED visits were recorded. All ED charts were coded by trained medical record nosologists using the International Classification of Diseases, 9th Revision (ICD-9) codes. The Health Research Ethics Board of the University of Alberta approved this main study protocol. The study was conceived and designed after March 31, 2002 (i.e., it is a retrospective study examining data produced between April 1, 1992 and March 31, 2002). These data are used in the retrospective study related to ambient air pollution exposure and health outcomes. ICD-9 codes 372.0-9 were applied to identify the conjunctivitis cases from the ED database. There were not any inclusion/exclusion criteria. 
Health outcomes measured as ED visits, daily averages of 24 hour concentration levels of ozone, daily average of temperature (dry bulb), and relative humidity were estimated for the period of the study. The environmental data were measured, recorded and provided by Environment Canada (for details, please see NAPS Web site: https://www.ec.gc.ca/rnspa-naps/).

2.2 Statistical analysis

A case-crossover (CC) method with a time-stratified approach to select the corresponding controls was used. In the CC method a person plays two roles; that of case and that of their own perfectly matched control on attributes that are not time-varying, such as age, sex, and comorbidity or similar characteristics. The exposure related to the event-period and to control-period(s) is considered and compared as the risk factor. For example, for any health case on October 18, 2017, the days October 4, 11 and 25 are the control days. We may apply the standard CC method in our analysis, but as the CC method works with individual events, it is better to use its equivalent modification [42-44]. In this way, there is smaller amount of data to process and to use in the related calculations. This approach (cases vs. counts) uses the daily counts rather than individual daily events. For example, 5 events in a specific day will result in 20 or 25 data records $(5$ cases and $5 \times 3=15$ or $5 \times 4=20$ controls) but will be used as 5 daily counts. In the standard CC method, logistic regression models are realized. In this presentation the CC method is realized by using conditional Poisson models [43].

In the constructed statistical models, temperature and relative humidity are represented in the form of natural splines to adjust for nonlinearity. These two weather factors are used as covariates in the constructed models. They were lagged by the same number of days as ambient ozone values.

Ground-level ozone was considered as the exposure. In the constructed models we used three forms of the transformation function $f(z)$, where $z$ is the amount of ozone, $z=\mathrm{O}_{3}$. These functions were $f(z)=z, f(z)=\log (z)$, and $\operatorname{sqrt}(z)$. In addition, these functions were regulated by the logistic weighting function. The constructed models used the product of $f(z)$ and the logistic functions to represent the exposure. The exposure $(\mathrm{z})$ was transformed and in such form was incorporated into the statistical model, controlling variation of the shape of the concentration-response functions $[2,45,46]$.

Representing the concentration levels by the variable $z$, we applied the following formula to calculate relative risk (RR) as the function of the variable $\mathrm{z}, R R(z)=\exp (\beta(z))$. The formula used for $\beta(z)$ has the following form

$$
\beta(z)=\beta * \frac{\mathrm{f}(z)}{1+\exp \left\{\frac{\mu-z}{r * \tau}\right\}},
$$

where $r$ is the range of the concentration levels, $\mu(\mathrm{mu})$ and $\tau$ (tau) are the parameters of the logistic function, where $\mathrm{mu}$ is a location parameter. The parameter tau controls the curvature of the weighting function. Larger values of tau produce shapes with less curvature. For given values of the parameters mu and tau we estimated the coefficient $\beta$ (Beta). We applied a case-crossover design to realize this study. Because we realized conditional Poisson models rather than conditional logistic regression models, we used the term relative risk rather than odds ratio.

We considered three transformation functions of the following forms $f(z)=z, \log (z), \sqrt{z}$. Using the results from other studies $[45,46]$ we considered only tau $=0.1$ and tau=0.2.

Here we fitted and tested six models, i.e. separately for each of three transformation functions, with two values (parameter tau; 0.1 and 0.2 ) of the curvature parameter. The best model is chosen among the evaluated six models (three forms of $f(z)$, and for each, two values of tau) applying the goodness of fit criterion. The methodology with sample data and codes is presented in [2].

Ozone and the weather parameters were lagged from 0 (the same day as ED visits for conjunctivitis) to 9 days (the exposure 9 days before the event day). For each lag and among the constructed six models we choose the method which gave the best fit. The quality of approximation was measured by the Akaike Information Criterion (AIC) value [47] (see also: https://en.wikipedia.org/wiki/Akaike_information_criterion). The model with the lowest AIC was classified as the best among used and tested. Calculations were done for all patients, males, and 
females. The included figures present the results for all patients, males and females. All calculations were performed using the R software (v. 3.5.1, ( ) 2018, The R Foundation for Statistical Computing).

\section{Results}

There were 17,211 ED visits for conjunctivitis: 9,046 (53\%) males, and 8,165 (47\%) females. Among the identified cases were the following number of ED visits and types: 5,019 (ICD-9: 372.0; Acute conjunctivitis), 1,635 (ICD-9: 372.1; Chronic conjunctivitis), 7,869 (ICD-9: 372.3; Others and unspecified conjunctivitis), 2,409 (ICD-9: 372.7; Conjunctival vascular disorders and cysts), and 280 cases for other types of conjunctivitis.

During 10 years of the study the frequency of ED visits for conjunctivitis by days of week was as follows: Sunday - number of cases: 3,318 (percentage of all visits: 19.3\%), Monday - 2,433 (14.1\%), Tuesday - 2,119 (12.3\%), Wednesday - 1,994 (11.6\%), Thursday - 2,063 (12.0\%), Friday - 2,353 $(13.7 \%)$, and Saturday $-2,931(17.0 \%)$. May, June and July were the months with the highest frequencies: 1,967 (11.4\%), 1,763 (10.2\%), 1,703 (9.9\%), respectively, and February was the month with the lowest number of visits: 1,050 (6.1\%).

As was already mentioned there were not any inclusion/exclusion criteria - cases were identified by using ICD-9 codes: 372.X. The postal-codes addresses were used to localize the patients in Edmonton.

The following daily (average of 24 hourly measurements) values were estimated for ozone (1.2, $11.3,17.9,18.7,25.3$, and 50.9, in ppb), temperature (-34.1, -4.0, 5.4, 3.9, 14.0, and 26.5, in ${ }^{\circ} \mathrm{C}$ ), and relative humidity $(25.1,57.1,66.2,66.0,75.6,98.5$, in $\%)$, as minimum value, $25^{\text {th }}$ percentile, median, mean, $75^{\text {th }}$ percentile, and maximum, respectively.

Table 1 summarizes the results for the six statistical models. It presents the lag (from 0 to 9 days), and the number of models (among six) which categorized the results as positive and statistically significant (estimated slope, Beta) at two levels of the criteria (P-Value): 0.05 and 0.2. For some lags we observed positive associations which was not statistically significant. Therefore, we used an additional criterion P-value $=0.2$ to verify if positive associations persisted for various models considered. It allows us to assess for associations when the results are not statistically significant. For lag 5 , this value in both cases is 6 , i.e. the estimated coefficient (Beta) was statistically significant $(P$-value $<0.05)$ for each of the six models.

Table 1. The best obtained models for the considered lagged exposure to ambient ozone.

\begin{tabular}{lllllll}
\hline Lag & $\mathbf{P}<\mathbf{0 . 0 5}$ & $\mathbf{P}<\mathbf{0 . 2}$ & Function & tau & mu & Beta \\
\hline 0 & 0 & 6 & $\log (\mathrm{z})$ & 0.1 & 29.3 & 0.0278 \\
1 & 0 & 4 & $\log (\mathrm{z})$ & 0.1 & 4.2 & 0.0266 \\
2 & 0 & 0 & $\mathrm{z}$ & 0.2 & -96.8 & 0.0026 \\
3 & 1 & 5 & $\log (\mathrm{z})$ & 0.1 & 16.1 & 0.0284 \\
4 & 0 & 5 & $\log (\mathrm{z})$ & 0.1 & 18.8 & 0.0248 \\
5 & 6 & 6 & $\log (\mathrm{z})$ & 0.1 & 18.6 & 0.0392 \\
6 & 0 & 0 & $\log (\mathrm{z})$ & 0.1 & -53.8 & 0.0081 \\
7 & 4 & 6 & $\log (\mathrm{z})$ & 0.1 & 8.64 & 0.0364 \\
8 & 0 & 0 & $\mathrm{z}$ & 0.1 & 18.5 & 0.0008 \\
9 & 0 & 2 & $\mathrm{z}$ & 0.2 & 40.5 & 0.0051 \\
\hline
\end{tabular}

Note: $\mathrm{P}(<0.05,<0.2)$ shows how many models classified the results as significant at the given level. In the case $\mathrm{P}<0.2$, the effect is observed but probably only a subset of ED visits is affected by ozone. Ozone: $\mathrm{z}=\mathrm{O}_{3}$. The estimated model (i.e. its main part directly related to the concentration-response) for the lags 0,1 , and 3-7 has the following form: $W(z)=$ Beta* $\log (\mathrm{z}) /(1+\exp ((\mathrm{mu}-\mathrm{z}) / \mathrm{rtau}))$, where $\mathrm{rtau}=\mathrm{r}^{*}$ tau, and $\mathrm{r}$ is the concentration range. The parameters $\mathrm{mu}$ and tau characterise the logistic function. According to the used specifications, the relative risk values $R R(z)=\exp (W(z))$. 
Figure 1 illustrates the number of ED visits for conjunctivitis by sex and age, where age is in years. Ages 85 and above (85+) are shown as one point. The analysis of the ED visits by sex resulted in the following associations which are presented in Table 2.

Table 2. The best obtained models for the considered lagged exposure to ozone by sex.

\begin{tabular}{lllllll}
\hline & \multicolumn{2}{c}{ Male } & \multicolumn{3}{c}{ Female } \\
\hline Lag & Beta & SE & mu & Beta & \multicolumn{1}{c}{ SE } & mu \\
\hline 0 & 0.0339 & 0.0262 & 34.8 & 0.0417 & 0.0262 & $15.6^{\mathrm{t}}$ \\
1 & $67.0421^{\mathrm{z}}$ & 68.9574 & $146.5^{\mathrm{t}}$ & $0.0652^{*}$ & 0.0288 & -0.7 \\
2 & -0.0299 & 0.0264 & $21.6^{\mathrm{t}}$ & $-5.718^{*_{z}}$ & 2.5807 & $112.6^{\mathrm{t}}$ \\
3 & $0.0013^{\mathrm{z}}$ & 0.0019 & 14.2 & $0.0391^{*}$ & 0.0199 & 15.1 \\
4 & 0.0238 & 0.0251 & $11.2^{\mathrm{t}}$ & 0.0268 & 0.0198 & 18.6 \\
5 & $0.0459^{*}$ & 0.0191 & 14.1 & $0.0034^{\mathrm{z}}$ & 0.0019 & 19.0 \\
6 & -0.0146 & 0.0330 & -51.2 & 0.0097 & 0.0207 & 12.0 \\
7 & 0.0367 & 0.0235 & 5.3 & 0.0373 & 0.0201 & 13.8 \\
8 & -0.0173 & 0.0325 & -15.3 & $0.0018^{z}$ & 0.0020 & 20.8 \\
9 & -0.0266 & 0.0311 & -8.1 & $0.0116^{* z}$ & 0.0055 & $46.1^{\mathrm{t}}$ \\
\hline
\end{tabular}

Note: ${ }^{\mathrm{z}}-\mathrm{f}(\mathrm{z})=\mathrm{z}$ identity was used, otherwise $\mathrm{f}(\mathrm{z})=\log (\mathrm{z}){ }^{\mathrm{t}}$ tau $=0.2$ was used, otherwise tau $=0.1$; SE - standard error, Ozone: $z=\mathrm{O}_{3}$. The estimated models with statistically significant coefficients (P-Value<0.05) are marked by a star*.

For males only, lag 5 indicates significant associations. For female patients, lag 1 and 3 have positive (lag 2 has negative) and statistically significant associations. The estimated associations are also positive for lags 5,7 , and 9, but non-significant (P-Value was greater than 0.05 but lower than $0.1)$.

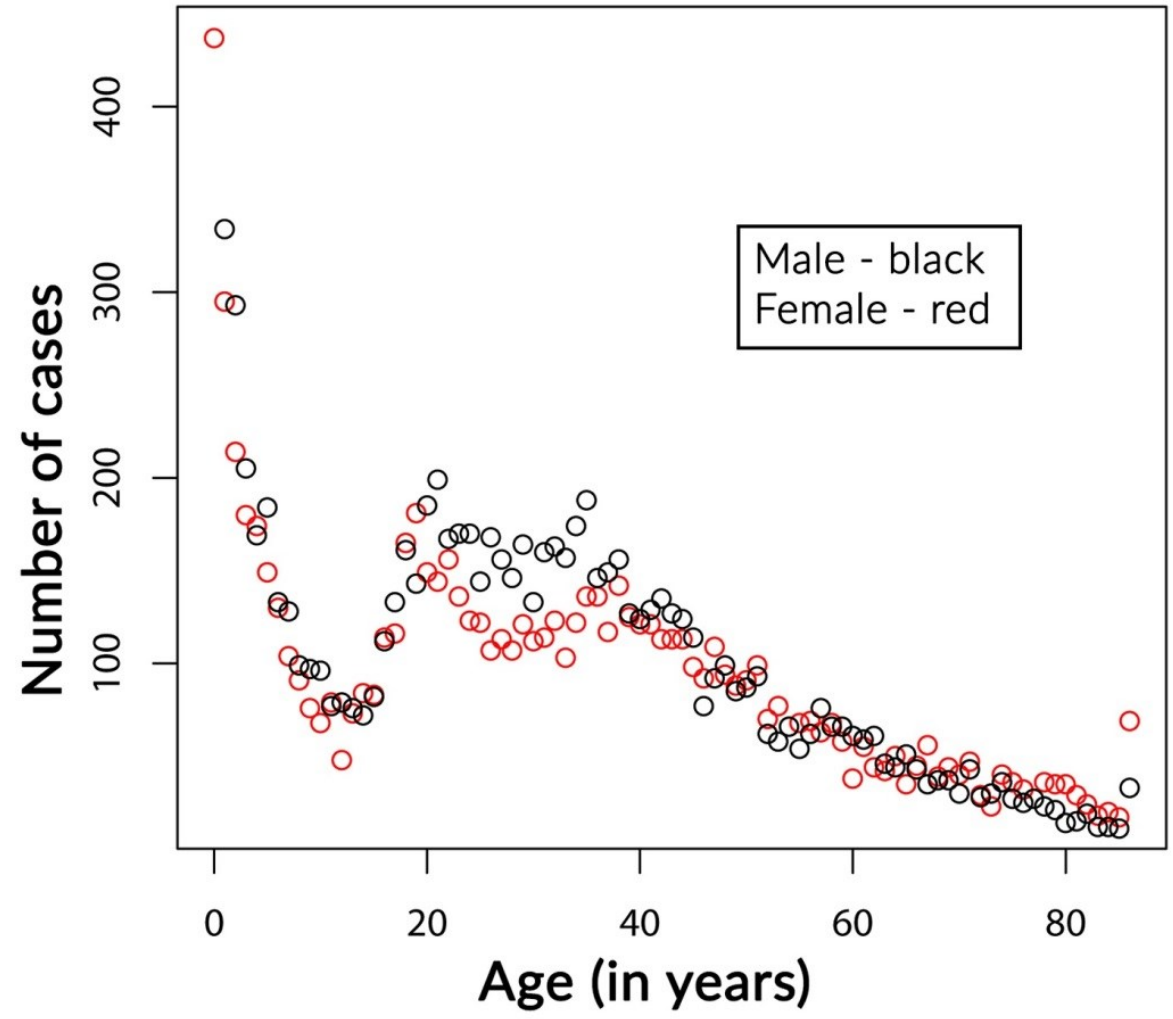

Canada.

Figure 1. Frequency of ED visits for conjunctivitis by sex and age. Edmonton, 1992-2002,

Figure 2 shows the results for the exposure lagged by 5 days for all patients. The association is positive and statistically significant (Table 1). The $95 \%$ confidence interval (95\% CI) is also shown (blue lines). 


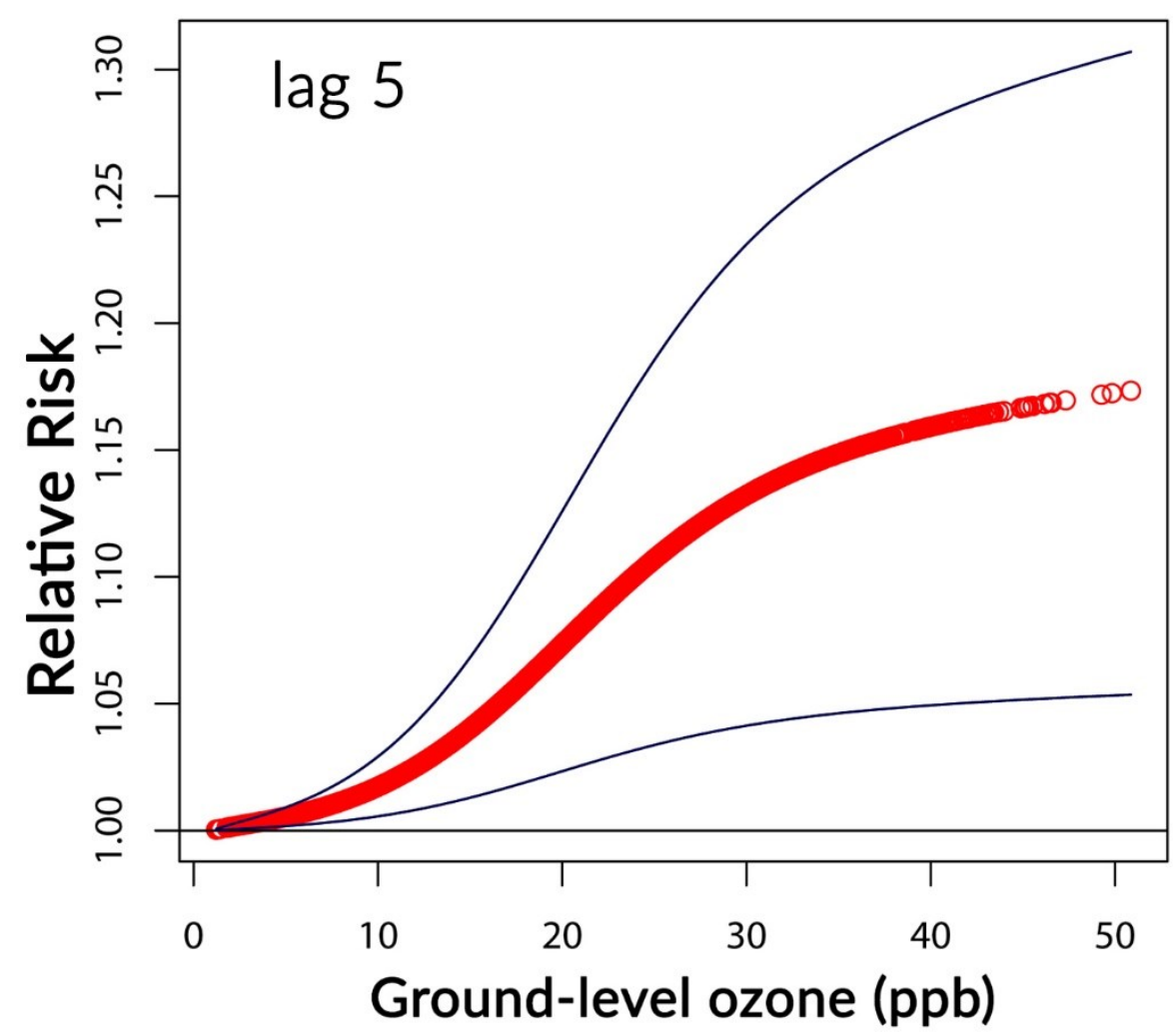

Figure 2. Concentration-response functions with $95 \% \mathrm{CI}$ for the exposure lagged by 5 days. All ED visits for conjunctivitis in Edmonton, 1992-2002, Canada.

Figure 3 illustrates the concentration-response functions generated by the best model (chosen among the six fitted) for the exposure related to lags $0,1,4$, and 6 . The standard CC method classifies the association for the lag 0,1 , and 4 as statistically non-significant. Using the methodology presented here, Figure 3 shows the association along the concentration for these lags. The panel for lag 6 shows that there is no association for the exposure on 6 days before the ED visit and the associations are not statistically significant (P-value $>0.05$ ) for lags $0-1$ and 4 .
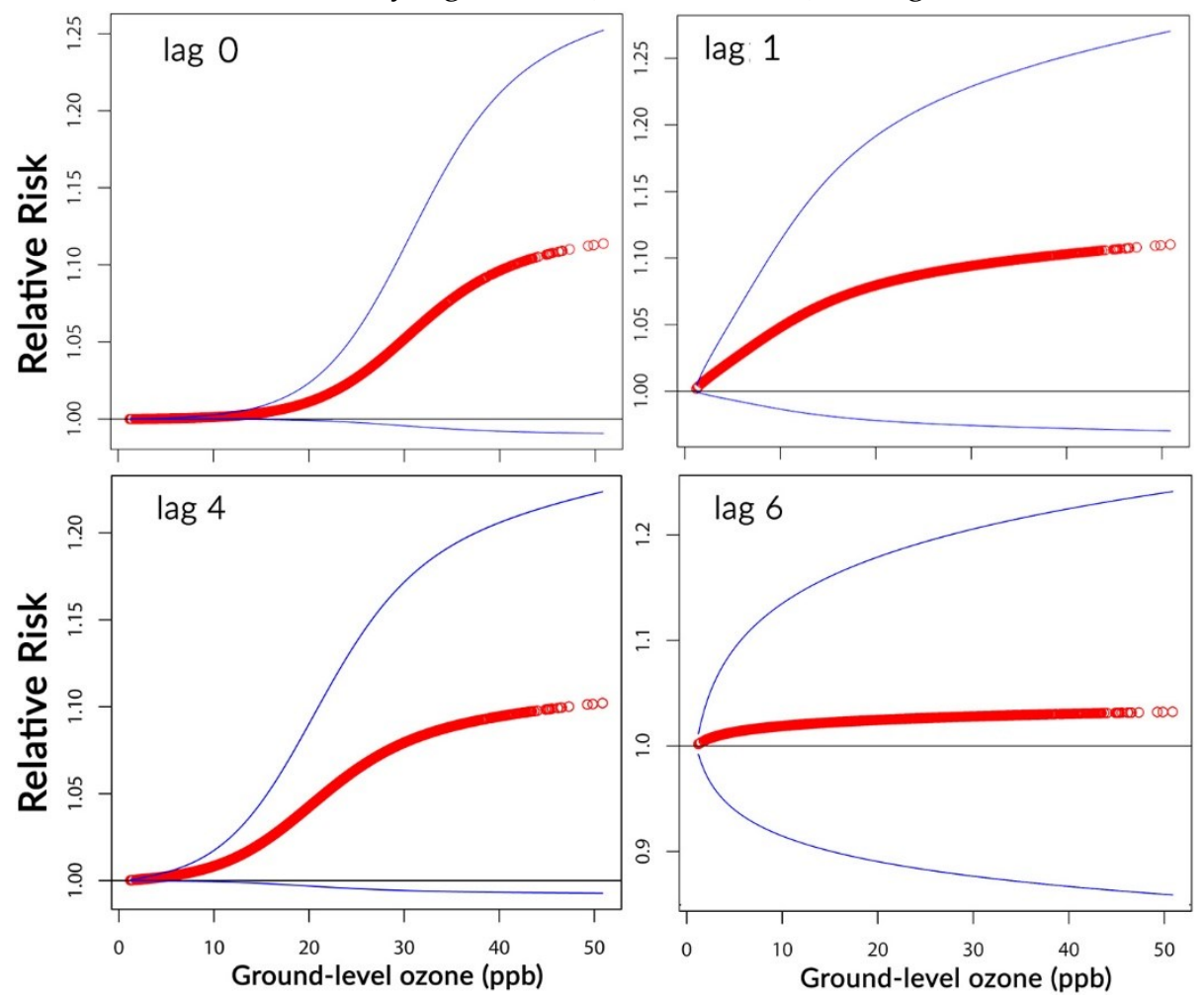
Figure 3. Concentration-response functions with 95\% CI for the exposure lagged by 0, 1, 4 and 6 days. All ED visits for conjunctivitis in Edmonton, 1992-2002, Canada.

\section{Discussion}

The statistical methods used in the present study are different from those realized in previous studies $[1,48,49]$, where mainly the standard case-crossover method is used and realized as a conditional logistic regression model. The main advantage of the analysis applied in this study is the use of a non-linear concentration-response functions in the form of a mathematical formula [2,45,46]. In addition, we applied several models and determined the best fit among the considered variants. The reader may use the estimated parameters (Beta, $\mathrm{mu}$, and tau) provided in Table 1, function $\mathrm{f}(\mathrm{z})$, and easily re-construct Figure 2, which is for the lag 5. This result agrees with Szyszkowicz et al. 2010 [1], where for log-linear model for lag 5 , the result was also statistically significant and positive. Of course, the same holds for other studied and presented models for the specified lags - using the estimated parameters it is possible to reconstruct concentration-response shapes.

Ozone poses high oxidative potential, and is able to cause damage to the ocular mucosa [50-52] and may provoke conjunctival inflammation via chemical modifications of aeroallergens and subsequent enhanced allergic response [36].

In this study we considered all ED visits identified as conjunctiva problems. Not all of them are associated with exposure to ozone. Different types of conjunctivitis (ICD-9 codes: 372.0 - 372.9) were analysed with the following assumptions: if health outcome A (a subset of conjunctivitis related to air pollution) has a positive association with an air pollutant, health outcome B has a neutral (non-) association, and health outcome $C$ has a negative association, then $A+C$ considered together will have a tendency to have a neutral association. In the $\mathrm{A}$ and $\mathrm{C}$ categories where the relations are opposite, positive vs. negative, they will reduce the associations to null. Other combinations such as: $\mathrm{A}$, and $\mathrm{A}+\mathrm{B}$, should have stronger associations than $\mathrm{A}+\mathrm{C}$. Among the considered ED visits for conjunctivitis are cases that don't depend on exposure to ozone (type B). We don't expect many negative associations (type C), i.e. such that are significantly negative. In our presentation we still observed the associations, even when we considered all cases and have a mixture of cases of different types $(A+B+C)$. In our situation we probably analysed the variant $A+B+C$, with a small number of the type $C$ cases. In other words, we expected positive associations or non-associations for ED visits for conjunctivitis and ozone. In one case (female, lag 2) we obtained statistically significant negative associations.

Figure 2 and 3 illustrate the shape of concentration-response related to exposure to ambient ozone and ED visits for conjunctivitis. We observed how this relationship changed along the concentration. It will be interesting to produce the concentration-response functions for other health outcomes. This was done previously, using the standard CC method, for 18 ICD-9 health groups to identify which air pollutants influence health [41]. The approach presented here is more precise, and can be used to qualify (give other estimates of the error) and quantify the air health effects.

\section{Conclusions}

The main findings of the presented study are: confirmation of the associations of ED visit for conjunctivitis with exposure to ambient ozone, and estimation of the form of these "associations" with 178 various concentration-response shapes, determine the best goodness of fit. The results agree with Szyszkowicz et al. 2010 [1] where, for log-linear model for lag 5, the estimated associations were also statistically significant and positive.

The strongest associations between exposure to ambient ozone and ED visits for conjunctivitis was estimated for the exposure lagged by 5 days.

We have to say that the observed inconsistency among the considered lags (for females: for lag 2 - negative, and for lag 5 - positive, statistically significant association) is not introduced by the presented methodology. The same type of the associations is estimated by using the standard time-stratified case-crossover method. 
Author Contributions: Formal analysis, Mieczysław Szyszkowicz, Ariela Gordon Shaag and Einat Shneor ; Investigation, Mieczysław Szyszkowicz and Ariela Gordon Shaag ; Methodology, Mieczysław Szyszkowicz; Software, Mieczysław Szyszkowicz; Validation, Ariela Gordon Shaag and Einat Shneor ; Visualization, Mieczysław Szyszkowicz; Writing - original draft, Mieczysław Szyszkowicz; Writing - review \& editing, Mieczysław Szyszkowicz, Ariela Gordon Shaag and Einat Shneor .

Funding: This research received no external funding.

Conflicts of Interest: The authors declare no conflict of interest.

\section{References}

1. Szyszkowicz M, Porada E, Gordon S, Rowe B. Ambient ozone and emergency department visits for skin conditions. Air Quality, Atmosphere \& Health. 2010;5:1-7.

2. Szyszkowicz M. Concentration-Response Functions for Short-term Exposure and Air Pollution Health Effects. Environmental Epidemiology Journal. April 25, 2018 - Volume Latest Articles - Issue - p doi: 10.1097/EE9.0000000000000011.

3. Fu Q, Mo Z, Lyu D, Zhang L, Qin Z, Tang Q, Yin H, Xu P, Wu L, Lou X, Chen Z, Yao K. Air pollution and outpatient visits for conjunctivitis: A case-crossover study in Hangzhou, China. Environ Pollut. 2017;pii: S0269-7491(17)33314-6.

4. Meeting the Eye Health and Vision Care Needs of Canadians: A Workforce Analysis A report from the Canadian Association of Optometrists. Prepared by Lisa Little Consulting, April, 2018. (Accessed on 28.02.1019; https://opto.ca/sites/default/files/resources/documents/workforce_analysis_final_april_2018.pdf

5. Azari AA, Barney NP. Conjunctivitis: a systematic review of diagnosis and treatment. JAMA. 2013 Oct 23;310(16):1721-9. doi: 10.1001/jama.2013.280318. Review. Erratum in: JAMA. 2014 Jan 1;311(1):95.

6. National Eye Institute (NEI), 2015 https://nei.nih.gov/health/pinkeye/pink_facts

7. Alabbasi OM, Al-Barry M, Albasri RF, Khashim HF, Aloufi MM, Abdulaal MF, Alsaidalany DW, Alahmadi AS, Habeeb H, Aalam WA. Patterns of ophthalmic emergencies presentinto a referral hospital in Medina City, Saudi Arabia. Saudi J Ophthalmol. 2017 Oct-Dec;31(4):243-246. doi: 10.1016/j.sjopt.2016.03.001.

8. Carvalaho RdeS, Jose NK. Ophthalmology emergency room at the University of São Paulo General Hospital: a tertiary hospital providing primary and secondary level care. Clinics [online]. 2007, vol.62, n.3, pp.301-308. ISSN 1807-5932. http://dx.doi.org/10.1590/S1807-59322007000300015.

9. Channa R, Zafar SN, Canner JK, Haring RS, Schneider EB, Friedman DS. Epidemiology of Eye-Related Emergency Department Visits. JAMA Ophthalmol. 2016 Mar;134(3):312-9. doi: 10.1001/jamaophthalmol.2015.5778.

10. Coles WH, Jaros PA. Dynamics of ocular surface pH. Br J Ophthalmol. 1984 Aug; 68(8): 549-552.

11. Torricelli AA, Novaes P, Matsuda M, Braga A, Saldiva PH, Alves MR, Monteiro ML. Correlation between signs and symptoms of ocular surface dysfunction and tear osmolarity with ambient levels of air pollution in a large metropolitan area. Cornea. 2013;32(4):e11-5. doi: 10.1097/ICO.0b013e31825e845d.

12. Liu H, Begley C, Chen M, Bradley A, ;Bonanno J, McNamara NA, Nelson JD, Simpson T. A Link between Tear Instability and Hyperosmolarity in Dry Eye. Cornea. 2009;Volume 50, Issue 8

13. Saxena R, Srivastava S, Trivedi D, Anand E, Joshi S, Gupta SK. Impact of environmental pollution on the eye. Acta Ophthalmol Scand. 2003;81(5):491-4.

14. Versura P, Profazio V, Cellini M, Torreggiani A, Caramazza R. Eye discomfort and air pollution. Ophthalmologica. 1999;213(2):103-9

15. Dartt DA. Interaction of EGF family growth factors and neurotransmitters in regulating lacrimal gland secretion. Exp Eye Res. 2004;78:337-345.

16. Pellegrini G, Golisano O, Paterna P, Lambiase A, Bonini S, Rama P, De Luca M. Location and clonal analysis of stem cells and their differentiated progeny in the human ocular surface. J Cell Biol. 1999;145(4):769-82.

17. Wei, Z. G., Cotsarelis, G., Sun, T. T. and Lavker, R. M. (1995). Labelretaining cells are preferentially located in fornical epithelium: implications on conjunctival epithelial homeostasis. Invest. Ophthalmol. Vis. Sci. 36,236246 
18. Berra M, Galperín G, Dawidowski L, Tau J, Márquez I, Berra A. Impact of wildfire smoke in Buenos Aires, Argentina, on ocular surface. Arq Bras Oftalmol. 2015 Mar-Apr;78(2):110-4. doi: 10.5935/0004-2749.20150028.

19. Novaes P, Saldiva PH, Matsuda M, Macchione M, Rangel MP, Kara-José N, Berra A. The effects of chronic exposure to traffic derived air pollution on the ocular surface. Environ Res. 2010;110(4):372-4. doi: $10.1016 / j$.

20. Torricelli AA, Novaes P, Matsuda M, Alves MR, Monteiro ML. Ocular surface adverse effects of ambient levels of air pollution. Arq Bras Oftalmol. 2011 Sep-Oct;74(5):377-81.

21. Torricelli AA, Matsuda M, Novaes P, Braga AL, Saldiva PH, Alves MR, Monteiro ML. Effects of ambient levels of traffic-derived air pollution on the ocular surface: analysis of symptoms, conjunctival goblet cell count and mucin 5AC gene expression. Environ Res. 2014 May;131:59-63. doi: 10.1016/j.envres.2014.02.014.

22. Tau J, Novaes P, Matsuda M, Tasat DR, Saldiva PH, Berra A. Diesel exhaust particles selectively induce both proinflammatory cytokines and mucin production in cornea and conjunctiva human cell lines. Invest Ophthalmol Vis Sci. 2013 Jul 16;54(7):4759-65. doi: 10.1167/iovs.12-10541.

23. Xiang P, He RW, Han YH, Sun HJ, Cui XY, Ma LQ. Mechanisms of housedust-induced toxicity in primary human corneal epithelial cells: Oxidative stress proinflammatory response and mitochondrial dysfunction. Environ Int. 2016 Apr-May;89-90:30-7. doi: 10.1016/j.envint.2016.01.008.

24. Leonardi A, De Dominicis C, Motterle L. Immunopathogenesis of ocular allergy: a schematic approach to different clinical entities. Curr Opin Allergy Clin Immunol. 2007;7(5):429-435. doi: 10.1097/ACI.0b013e3282ef8674.

25. Mudway IS, Kelly FJ. Ozone and the lung: a sensitive issue. Mol Aspects Med. 2000 Feb-Apr;21(1-2):1-48.

26. Lee HS, Schlereth $S$, Khandelwal P, Saban DR. Ocular allergy modulation to hi-dose antigen sensitization is a Treg-dependent process. PLoS One. 2013 Sep 27;8(9):e75769. doi: 10.1371/journal.pone.0075769. eCollection 2013

27. Lee H, Kim EK, Kim HY, Kim TI. Effects of Exposure to Ozone on the Ocular Surface in an Experimental Model of Allergic Conjunctivitis. PLoS One. 2017 Jan 3;12(1):e0169209. doi: 10.1371/journal.pone.0169209. eCollection 2017 Erratum in: PLoS One. 2017 Feb 28;12 (2):e0173328.

28. Ramirez DA, Porco TC, Lietman TM, Keenan JD. Epidemiology of Conjunctivitis in US Emergency Departments. JAMA Ophthalmology October 2017 Volume 135, Number 10.

29. Szyszkowicz M, Kousha T, Castner J. Air pollution and emergency department visits for conjunctivitis: A case-crossover study. Int J Occup Med Environ Health. 2016;29(3):381-93.

30. Geraldini M, Chong Neto HJ, Riedi CA, Rosario NA. Epidemiology of ocular allergy and co-morbidities in adolescents. Jornal de Pediatria. 2013; 89:354-360.

31. Kumah DB, Lartey SY, Yemanyi F, Boateng EG, Awuah E. Prevalence of allergic conjunctivitis among basic school children in the Kumasi Metropolis (Ghana): a community-based cross-sectional study. BMC Ophthalmol. 2015 Jul 3;15:69. doi: 10.1186/s12886-015-0053-8.

32. Jung SJ, Mehta JS, Tong L. Effects of environment pollution on the ocular surface. Ocul Surf. 2018;16(2):198-205. doi: 10.1016/j.jtos.2018.03.001.

33. Chang CJ, Yang HH, Chang CA, Tsai HY. Relationship between air pollution and outpatient visits for nonspecific conjunctivitis. Invest Ophthalmol Vis Sci. 2012;53(1):429-33. http://dx.doi.org/10.1167/iovs.11-8253.

34. Kousha T, Castner J. Conjunctivitis: Etiology, Diagnosis and Clinical Management Air Pollution and Emergency Department Visit for Conjunctivitis in Calgary, Canada: A Case Crossover Study. Nova Publisher ebook: Eye and Vision Research Developments. 2010 ISBN: 978-1-63321-661-7.

35. Mimura T, Ichinose T, Yamagami S, Fujishima H, Kamei Y, Goto M, Takada S, Matsubara M. Airborne particulate matter (PM2.5) and the prevalence of allergic conjunctivitis in Japan. Sci Total Environ. 2014 Jul 15;487:493-9. doi:10.1016/j.scitotenv.2014.04.057.

36. Hong J, Zhong T, Li H, Xu J, Ye X, Mu Z, Lu Y, Mashaghi A, Zhou Y, Tan M, Li Q, Sun X, Liu Z, Xu J. Ambient air pollution, weather changes, and outpatient visits for allergic onjunctivitis: A retrospective registry study. Sci Rep. 2016 Apr 1;6:23858. doi: 10.1038/srep23858.

37. Li Z, Bian X, Yin J, Zhang X, Mu G. The Effect of Air Pollution on the Occurrence of Nonspecific Conjunctivitis. J Ophthalmol. 2016;Article ID 3628762

38. Nucci P, Sacchi M, Pichi F, Allegri P, Serafino M, Dello Strologo M, De Cillà, Villani E. Pediatric Conjunctivitis and Air Pollution Exposure: A Prospective Observational Study. Semin Ophthalmol. 2017;32(4):407-411. 
39. Szyszkowicz M, Porada E, Kaplan GG, Rowe BH. Ambient Ozone and Emergency Department Visits for Cellulitis. Int J Environ Res Public Health.2010;7(11): 4078-4088.

40. Szyszkowicz M, Porada E, Kaplan GG, Grafstein E -2012 Ambient Ozone as a Risk Factor for ED Visits for Cellulitis. Environment and Pollution. 2012;1: 105

41. Szyszkowicz M, Rowe BH. Respiratory Health Conditions and Ambient Ozone: A Case-Crossover Study. Insights Chest Dis. 2015;1:9.

42. Szyszkowicz M. Use of generalized linear mixed models to examine the association between air pollution and health outcomes. Int J Occup Med Environ Health.2006;19(4):224-7.

43. Armstrong BG, Gasparrini A, Tobias A. Conditional Poisson models: a flexible alternative to conditional logistic case cross-over analysis. BMC Med Res Methodol. 2014;14:122.

44. Szyszkowicz M, Burr WS. The use of chained two-point clusters for the examination of associations of air pollution with health conditions. Int J Occup Med Environ Health. 2016;29(4):613-22.

45. Nasari MM, Szyszkowicz M, Chen H, Crouse D, Turner MC, Jerrett M, Pope CA 3rd, Hubbell B, Fann N, Cohen A, Gapstur SM, Diver WR, Stieb D, Forouzanfar MH, Kim SY, Olives C, Krewski D, Burnett RT. A class of non-linear exposure-response models suitable for health impact assessment applicable to large cohort studies of ambient air

46. Burnett R, Cheng H, Szyszkowicz M, Fann N, Hubbell B et al. Global Estimates of Mortality Associated with Long Term Exposure to Outdoor Fine Particulate Matter. Proc Natl Acad Sci U S A. 2018;115(38):9592-9597. doi:10.1073/pnas.1803222115.

47. Akaike H. Information theory as an extension of the maximum likelihood principle. In B.N. Petrov, F. Csaki (Eds.), Second International Symposium on Information Theory, Akademiai Kiado, Budapest (1973), pp. 267-281.

48. Maclure M. The case-crossover design: a method for studying transient effects on the risk of acute events. Am J Epidemiol. 1991;133(2):144-153.

49. Janes H, Sheppard L, Lumley T. Case-crossover analyses of air pollution exposure data. Referent selection strategies and their implications for bias. Epidemiology. 2005;16(6):717-726.

50. Novaes P, do Nascimento Saldiva PH, Kara-José N, Macchione M, Matsuda M, Racca L, Berra A. Ambient levels of air pollution induce goblet-cell hyperplasia in human conjunctival epithelium. Environ Health Perspect. 2007 Dec;115(12):1753-6.

51. Rozanova E, Heilig P, Godnic-Cvar J. The eye--a neglected organ in environmental and occupational medicine: an overview of known environmental and occupational non-traumatic effects on the eyes. Arh Hig Rada Toksikol.2009; 60(2):205-15. doi: 10.2478/10004-1254-60-2009-1869.

52. Fujishima H, Satake Y, Okada N, Kawashima S, Matsumoto K, Saito H. Effects of diesel exhaust particles on primary cultured healthy human conjunctival epithelium. Ann Allergy Asthma Immunol. 2013 Jan;110(1):39-43. doi: 10.1016/j.anai.2012.10.017. 